\title{
Dependence on Cultural Contexts of the Factors Influencing Social Acceptance toward Schizophrenia: Evidence from Comparative Study between Japan and Vietnam
}

\author{
Mari HIGUCHI ${ }^{1}$ \\ ${ }^{1}$ Graduate School of Human Sciences, Osaka University, Suita City, Osaka, Japan \\ Correspondence: Mari HIGUCHI, Graduate School of Human Sciences, Osaka University, 1-2, Yamada-oka, \\ Suita-shi, Osaka, 565-0871, Japan. Tel: 81-06-6875-8069. E-mail: marie.hirota.higuchi@gmail.com
}

Received: November 5, 2014

Accepted: July 6, 2015 Online Published: August 18, 2015

doi:10.5539/ass.v11n22p187

URL: http://dx.doi.org/10.5539/ass.v11n22p187

\begin{abstract}
This paper explores the factors influencing social acceptance toward persons with schizophrenia by examining the effects of perceived dangerousness, having knowledge, and social instability and investigates these conditions in a cross-cultural comparison of Japan and Vietnam. Social distance scales and random sample survey questionnaires based on vignettes were used to reconstruct social acceptance in Japan $(n=488)$ and Ho Chi Minh City in Vietnam $(\mathrm{n}=185)$. Structural equation modeling was applied to explore the relation between social acceptance, perceived dangerousness, beliefs in Western psychiatric treatments, contact with people with schizophrenia, and cohorts having grown up during the Vietnam War.

In both countries, contact reduced the perceived dangerousness of persons with schizophrenia and increased their social acceptance. Beliefs in Western psychiatric treatments informed by education-based knowledge, however, intensified perceived dangerousness in Japan, but increased social acceptance in Vietnam. The effects of education-based knowledge emerge differently according to each society's mental health system history. The Vietnamese cohort born during the Vietnam War showed greater social acceptance than others, while no effects were observed in Japanese cohorts. Social instability seems to change social values and negative social attitudes related to schizophrenia.
\end{abstract}

Keywords: Asian countries, cross-cultural study, schizophrenia, social acceptance, sociology, structural equation modeling

\section{Introduction}

\subsection{The Importance of Social Acceptance}

Social attitudes toward persons with mental health problems are closely linked to political decisions and mental health service policies. After psychiatry emerged in Western Europe as a medical domain, the confinement of "patients" to psychiatric wards in the name of protecting the public was enforced. In recent years, most developed countries have tried shifting mental health services "from institutionalization to deinstitutionalization," including financial aspects and the human rights of patients. During this political transition, medical professionals, politicians, and the public need to reconsider why people with chronic mental disorders have been penned in psychiatric wards and how they can change such stigmatizing attitudes toward them. To create an environment that allows people with chronic mental disorders and the public to coexist and lead satisfying lives, it is essential to understand how the public presently regards living in the same community with them.

In this paper, I define public view of living with people having chronic mental disorders as social attitudes. A great deal of research has been conducted measuring social attitudes, especially in psychiatric epidemiology. These studies indicated the following three characteristics of social attitudes: (a) persons with schizophrenia are the most stigmatized and less expected to live and socialize in communities with others compared to those with other mental health problems (Durand-Zaleski, Scott, Rouillon, \& Leboyer, 2012; Griffiths et al., 2006; Lauber, Nordt, Falcato, \& Rössler, 2004); (b) the perceived dangerousness of persons with mental health problems is a primordial factor leading to negative social attitudes and stereotypes, particularly related to schizophrenia (Angermeyer, 2003; Durand-Zaleski et al., 2012); (c) social attitudes and the degree of tolerance toward people 
with schizophrenia orients the outcomes of their disorder (Warner, 1994). Additionally, people with schizophrenia feel that they experience prejudice related to their perceived dangerousness (González-Torres, Oraa, Arístegui, Fernández-Rivas, \& Guimon, 2007). As a result, patients living in communities tend to avoid having intimate relationships or stop themselves from applying for work opportunities for fear of being discriminated (Uçok et al., 2012). Exclusion, which leads to a decline in the quality of life of deinstitutionalized patients, has been one of the greatest obstacles in promoting their social inclusion. In this paper, I focus on the factors that inform social attitudes toward persons with schizophrenia by constructing hypotheses based on recent studies.

\subsection{The Knowledge Hypothesis}

Findings from current studies in developed countries in Western Europe, North America, and Asia, particularly Japan - where Western pharmacological treatments were adopted as a first choice in mental health care - have been applied to educational programs to reduce negative social attitudes toward persons with schizophrenia. These educational programs, such as the World Psychiatric Association's anti-stigma program (The World Psychiatric Association, 2005), aim to improve the public's "mental health literacy (Jorm et al., 1997)". Jorm et al. (Jorm et al., 1997, p. 183) defined mental health literacy by extending the term "health literacy" and explained it as "the ability to recognize specific disorders, knowing how to seek mental health information, knowledge of risk factors and causes, of self-treatments, and of professional help available, and attitudes that promote recognition and appropriate help-seeking."

Medical professionals and researchers have led the campaign for mental health literacy, assuming that education would decrease tensions between the public and persons with schizophrenia (Kelly, Jorm, \& Wright, 2007). Acquiring mental health literacy is considered to promote public recognition of a behavioral or psychological deviation as a "mental disorder," which leads to greater acceptance of psychiatric treatments. In addition, it was expected that if people recognized the effectiveness of Western psychiatric treatments they would consult psychiatrists or medical professionals without fearing or experiencing social rejection, which might shorten the "duration of untreated periods" (DUP). The main objective of medical professionals is early intervention. Several studies emphasize better outcomes for treating schizophrenia because of early medical intervention (Marshall et al., 2005; Primavera et al., 2012; Thirthalli et al., 2011).

Education and studies on social attitudes have been conducted, albeit without sufficient investigation on how knowledge or mental health literacy influences negative social attitudes. They may have limited effects or unexpected outcomes that need to explore with controlling the effects of schizophrenia's perceived dangerousness. Tanaka et al. evaluated the effects of lectures on mental health and found that acquiring knowledge about mental health problems promoted help-seeking behavior and agreements with mental health services (Tanaka et al., 2003). Conversely, certain attitudes - expectations regarding the patients' ability to participate in a social life - did not change significantly afterwards (Tanaka et al., 2003). Similarly, the perceived peculiarity of schizophrenia (Tanaka et al., 2004) and willingness to interact with persons with schizophrenia were reported in other studies (Mino et al., 2001; Pinfold et al., 2003; Pinfold et al., 2005). Although these studies mention the ineffectiveness of educational programs in creating mental health literacy, further investigations need to be done.

Most studies examined the factors that increased/decreased stigmatizing social attitudes by multiple or logistic regression analysis. Their limitations can be summarized as follows: The socio-demographic and psychological factors, including schizophrenia's perceived dangerousness, were examined as independent variables in regression analyses, but the causal results direction between socio-demographic and psychological factors were not examined. The models adopted in the studies could define neither what kinds of socio-demographic factors increase/decrease schizophrenia's perceived dangerousness nor how acquiring knowledge influences it and other social attitudes. Consequently, the following issue remains unresolved: "acquiring more detailed mental health knowledge can increase negative social attitudes, which is the paradoxical outcome of enlightenment practices (Nakane, 2010)."

The factors moderating and consequently reducing negative social attitudes are based on intimate experiences or interactions with persons who have schizophrenia or other chronic mental disorders (Desforges et al., 1991; Lauber et al., 2004; Yamaguchi et al., 2013; Yamaguchi, Mino, \& Uddin, 2011). These interactions are referred to in the "contact hypothesis (Allport, 1979)." Brown derived four premises to elicit the most positive effects of contact: "social and institutional support, acquaintance potential, equal status, and co-operation (Brown, 1995)." These premises support results that indicate that short and temporary contact does not influence negative attitudes toward those with chronic mental disorder (Cutler et al., 2012). The type of contact that promotes 
positive social attitudes depends on the person with schizophrenia's position in relation to his/her family members. If family members undertake a person's care legally and informally, their contact is supported societally and institutionally, especially in East Asian countries. Also, this contact is durable with a certain level of frequency and constructs a meaningful relation between the family and the person with schizophrenia. This is compatible with the premises of "acquaintance potential," as well as "co-operation," which can reflect the situation in their daily lives. People with schizophrenia are also expected to have frequent opportunities to have contact with others with mental disorders because they are encouraged to participate in day-care or communal activities, such as self-help groups. Accordingly, similar effects to those of the contact hypothesis are supposed to be observed within them. It is pertinent to say that the knowledge of schizophrenia that one obtains through real interactions should be distinguished from that which is obtained through educational lectures.

In this paper, I elaborate on the inconsistent effects of knowledge and propose that its relation to mental health literacy has two contradictory effects on social attitudes. On one hand, knowledge about schizophrenia increases confidence in Western psychiatric treatments; on the other, it decreases socially tolerant attitudes toward persons with the disorder, such as a willingness to initiate relationships with them. Since most Western psychiatric hospitals in developed countries were historically "asylums (Goffman, 1961)," people often regard mental health services as systems of surveillance for persons with chronic mental disorders rather than scientifically effective treatments. The promotion of mental health literacy may contribute to the decline of skepticism toward Western psychiatric treatments and the increased recognition of their medical effectiveness. As indicated in previous studies, knowledge gained from educational programs has some "positive" effects; however, when people consider real situations in their daily lives, few have contact with persons with schizophrenia because of the history of isolation of psychiatric patients within hospitals. The stereotype of dangerousness has been shared and kept within society without being modified or questioned. If people acquire the knowledge of symptoms, the effectiveness of treatments, or of the convalescence process of schizophrenia through education it is assumed that the behavior of those with schizophrenia is "medically deviant" and difficult to control or change without medical intervention. Contrary to the expectations of educational programs, mental health knowledge maintains or rather reinforces negative social attitudes and can be viewed as evidence of the public's suspicion of dangerousness. Though knowledge should provide opportunities to create doubt regarding stereotypes related to persons with schizophrenia, it may instead emerge from real experiences and intimate contact with them. I refer to these two contrasting effects of knowledge as the knowledge hypothesis. To improve education to reduce negative social attitudes, this hypothesis needs to be examined.

\subsection{Social Instability Hypothesis}

This paper also examines another hypothesis that examines how views of different generations vary in relation to mental health. Several sociological studies indicated that moral precepts and values that are important to daily life vary according to the historical period in which one has grown up (Elder, 1984; Inglehart, 1990). Generations that grew up during social fluctuations such as wars or serious economic stagnation attach greater importance to material affluence than those who have not (Inglehart, 1990). Past psychiatric epidemiology studies on social attitudes toward persons with schizophrenia examined the role of generation as a linear variable of age (Lauber et al., 2004; Tanaka et al., 2003). There has not, however, been adequate inquiry regarding the influence of social change on specific generations. Therefore, it is difficult to identify whether the variable of age reflects generational experiences or influence of life stage that exists separately from generation and the times. In addition, it cannot be ignored that attitudes toward schizophrenia can vary according to where a person lives because a society's values often determine its views on mental disorders (Warner, 1994). In more developed and industrialized societies, those with schizophrenia are isolated because economic productivity, which difficult for most of them, is highly valued. On the contrary, there is still a chance that those affected can be integrated into communities, instead of isolation, in developing societies. Their "psychiatric symptoms" are considered as a sign that their families or persons close to them should gather to re-enforce their bonds of intimacy (Warner, 1994). Although there is no clear indication showing at what point social attitudes shift from acceptable to rejectable and the conditions that change societal values affecting schizophrenia have not been investigated enough, it can be assumed that social instability is one of the key factors that changes social attitudes. This influence is apparent in certain cohorts. I hypothesize that the generations who have grown up in socially unstable environments acquire different attitudes toward people with schizophrenia (social instability hypothesis).

\subsection{The Need for Cross-cultural Comparison}

This study defines social acceptance as tolerant and constructive attitudes toward those affected by schizophrenia and examines this by testing knowledge and social instability hypotheses. As I explain in the chapter of methods, social acceptance was measured based on the respondents' willingness to become neighbors of, to work with, or 
to build a family through marriage with someone who has schizophrenia. To test the knowledge hypothesis, I adopted two different variables to separately measure the effects of education-based knowledge and that of contact experience: the first identifies whether the survey participants have confidence in Western psychiatric treatments and the second determines whether they have schizophrenia or are related to someone who does. The difference in social attitudes between generations can be observed as an effect of cohort variable in statistical analysis. The social instability hypothesis can then explore the influence of social instability on certain cohorts.

Both hypotheses should be examined by exploring cross-cultural data gathered from societies with different mental health system histories. It would be difficult to recognize whether the effects of education-based or contact-based knowledge emerge only in one society or globally using a single society's data. One would not be able to conclude that the effects observed in a certain cohort represent the influence of social instability; similar effects may appear in another society and be attributed to aging alterations or other global factors.

Therefore, it is necessary to compare two types of societies: one that has a history of using asylums and another that does not. One of the two must also include a generation having undergone remarkable social change compared to the other. In this study, I used data from Japan and Vietnam, since they meet the criteria of both hypotheses. Japanese mental health services are based on Western treatments that consist of anti-psychotic medications administered by psychiatrists in a system that has a history of extended stays in psychiatric wards. Even today in Japan, schizophrenia patients' average length of stay in psychiatric wards is 561.1 days (Ministry of Health, 2011) and the number of psychiatric beds is 342,194 (Ministry of Health, 2012) which corresponds to 26.8 beds per 10,000 population. On the contrary, Western psychiatry was imported into Vietnam from France during mid- $19^{\text {th }}$ century; however, only one psychiatric hospital has existed in outskirts of Ho Chi Minh city to receive a large number of patients (Yamamoto, 2001) and traditional treatments are still used in spite of legal prohibition (Uemoto \& Miura, 2012). In addition, 0.60 psychiatric beds are provided per 10,000 population in Vietnam (Vuong et al., 2011). Considering the constant shortage of psychiatrists, small number of beds and short hospital stays - not exceeding several weeks (Uemoto, 2009), it can be said that Western psychiatric treatments did not become the standard choice of Vietnamese people. The Vietnamese mental health system does not have the same history of using asylums as do Japan and other occidental countries. In addition, the Vietnam War from 1961 to 1976 left terrible scars on the Vietnamese people, whereas Japan was not confronted with any remarkable social change during this time. I therefore created cohort variables that represent the generations that grew up during the Vietnam War.

\subsection{Aims of the Study}

To investigate the factors that determines the social acceptance of persons with schizophrenia using the following hypotheses (HP):

(HP-1) The perceived dangerousness of persons with schizophrenia is related to the decline of social acceptance.

(HP-2) In attempts to control the perception that people with schizophrenia are dangerous, education-based knowledge decreases social acceptance and contact-based knowledge and experience increases social acceptance.

(HP-3) Cohorts that grew up in socially unstable environments are more socially accepting than those that have not.

\section{Methods}

\subsection{Data}

The Japanese data, originally intended to be compared to Australian surveys from 2003 to 2004, is drawn from Japanese Survey of Mental Health Literacy ("Seishin Hoken no Chisiki to Rikai ni kansuru Tyousa": in Japanese) conducted by Y. Nakane and K. Yoshioka in 2003. This study is a secondary analysis of this data. Their survey comprised common questions about social attitudes for case vignettes: chronic schizophrenia, early-episode schizophrenia, depression, and depression with suicidal thoughts (Nakane et al., 2005). The description of vignettes was designed to fit the diagnostic criteria of DSM-IV and ICD-10. Respondents were randomly shown male or female versions of the vignettes (Nakane et al., 2005). The target populations of these two surveys were male and female aged 20 to 69 . The chronic schizophrenia vignette was chosen for this study, since chronic symptoms are the most obstructive factors to community living and social acceptance. The outline of the chronic schizophrenia vignette is as follows: an unemployed male or female is described as passing a day in the park talking to himself/herself. Also, the person affected says that he/she is under surveillance because he/she knows a secret regarding an international computer system that can control everyone the world over. The questions from the Australian survey were translated into Japanese and their accuracy was confirmed by being retranslated into 
English.

Instead of using a national survey of randomly selected households, they first divided Japan into five geographical regions. Next, they selected five cities within each region according to city size, number of psychiatric beds and the rate of suicide to identify 25 sites for the project. After that, home interviews were conducted in 500 randomly selected households. (Note 1) Responses were collected until the required number of participants in each age and gender category was received. Thus, a refusal rate was not relevant in this survey. More information about procedural details is provided in Nakane et al. (2005).

Uemoto and Miura (2012) conducted the Vietnamese survey from 2007 to 2008 in Ho Chi Minh City. This study is a primary analysis of that data. In the sampling process, each district of Ho Chi Minh City was used. (Note 2) Furthermore, in each site, the required number of sampling cases in age and gender categories were determined based on Ho Chi Minh City's demographical structure of persons aged 18 to 74. Finally, home interviews were conducted in randomly selected households.

This survey was designed for comparison with the Japanese survey that Uemoto and his colleagues translated into Vietnamese, based on the Japanese and Australian versions. The validity of the translation was ensured using the same procedure described earlier. Though it relied on home interviews equivalent to those in the Japanese survey, two vignettes about chronic and early-episode schizophrenia were substituted. The Vietnamese sample size of 295 responses about chronic schizophrenia and 195 about early-episode schizophrenia. The refusal rate was also not reported in this survey (Uemoto \& Miura, 2012). The details of the Vietnamese survey have been explained by Uemoto and Miura (Uemoto \& Miura, 2012).

\subsection{Dependent Variable}

I used the social distance scale developed by Link et al. to measure social acceptance (Link et al., 1999). In the analysis, I selected the following three questions to extract the same factor structure for both Japan and Vietnam:

Q: How willing would you be to move next door to A-o (B-ko)?

Q: How willing would you be to make friends with A-o (B-ko)?

Q: How willing would you be to have A-o (B-ko) marry into your family?

"A-o" signifies an anonymous Japanese male name and B-ko corresponds to an anonymous Japanese female name. In the Australian questionnaire, the names in the vignettes were John and Mary. The values of each question ranged from ( i ) "Definitely willing" to (iv) "Definitely unwilling." The "Don't know" (DK) option was included in the Vietnamese survey and excluded in Japan. Instead, "Strongly unwilling" was added in Japanese survey as a fifth value. There were no DK answers in the Japanese data. For the factor analysis, I excluded the DK answers in the Vietnamese data; combined the "strongly unwilling" to "definitely unwilling" responses in the Japanese data; and reversed the values of these variables. A growing number means that respondents are more willing to interact with a person that has schizophrenia.

\subsection{Independent Variables}

The independent variables were grouped based on two major factors: socio-demographic and psychological recognition. For socio-demographic factors, I adopted gender ( $\mathrm{male}=1$, female $=0$ ), years of education (from 6 to 16 years), marital status (single $=1$, married $=0$ ), cohort, and "person concerned" representing the respondents' experience of contact. In the analysis, gender, years of education, marital status was treated as controlled variables. Based on my hypothesis regarding social instability, I divided the age variable into three dummy cohorts, according to different periods of the Vietnam War. In both surveys, the respondents were organized according to age in five-year strata, expect those more than 74 years old in Vietnamese survey. The "cohort born before the Vietnam War" was 55-69 years old in Japan and over 55 years old in Vietnam. The "cohort born during the Vietnam War" was 40-54 years old in both countries. The "cohort born after the Vietnam War" was 18-39 years old in both countries. The "person concerned" variable combined two questions that asked respondents if they ever had similar problems to those presented in the vignettes or if anyone in their family or close circle of friends had. Respondents scored " 1 " if they gave a positive response and a negative response scored " 0. "

Psychological factors consisted of two variables: "perceived dangerousness" and "beliefs in Western psychiatric treatment." Using five response categories ranging from ( i ) "Strongly disagree" to (v) "Strongly agree," perceived dangerousness was measured using the following idea:

Q: People with a problem like A-o (B-ko) are dangerous.

Belief in Western psychiatric treatments was confirmed using factor analysis when running structural equation 
modeling (SEM) for the following two variables: those who were asked about the effectiveness of help provided by a psychiatrist and of hospitalization in psychiatric wards. A higher score signifies that respondents regard psychiatrists and hospitalization as helpful and have a greater confidence in Western psychiatric treatments. The response of "neither" was pointed between that of "harmful" and "helpful."

Q: Is a psychiatrist likely to be helpful, harmful, or neither for A-o (B-ko)?

Q: Do you think being admitted to the psychiatric ward of a hospital is likely to be helpful, harmful, or neither for A-o (B-ko)?

\subsection{Statistical Methods}

First, I conducted a factor analysis to extract the dependent variable - "social acceptance" - from the three previously mentioned variables and examined whether perceived dangerousness decreased in both countries, corresponding to the data in other studies. From a second analysis, I extracted the "Beliefs in Western psychiatric treatment" from the two variables discussed earlier. A regression analysis was used to explore the relation between social acceptance, socio-demographic factors, and the belief in Western psychiatric treatments to control the effects of perceived dangerousness of persons with schizophrenia. Missing data were excluded in all analyses.

The data were analyzed using two statistical software programs, SPSS Version 21 and the Mplus Version 7. To estimate the effects of socio-demographic factors and beliefs in Western treatments, I adopted structural equation modeling (SEM) for multi-group analyses. The SEM simultaneously carries out both regression and factor analyses and generates a model fitting the data. Additionally, the SEM shows the direction of causes and results by fixing and examining the model's fitness. The three variables - "Belief in Western psychiatric treatments," "Person concerned," and "Cohorts" - were regarded as causes and "Social acceptance" as a fixed result in the SEM.

\section{Results}

\subsection{General Tendencies in Vietnam and Japan}

Table1. Descriptive statistics of all variables

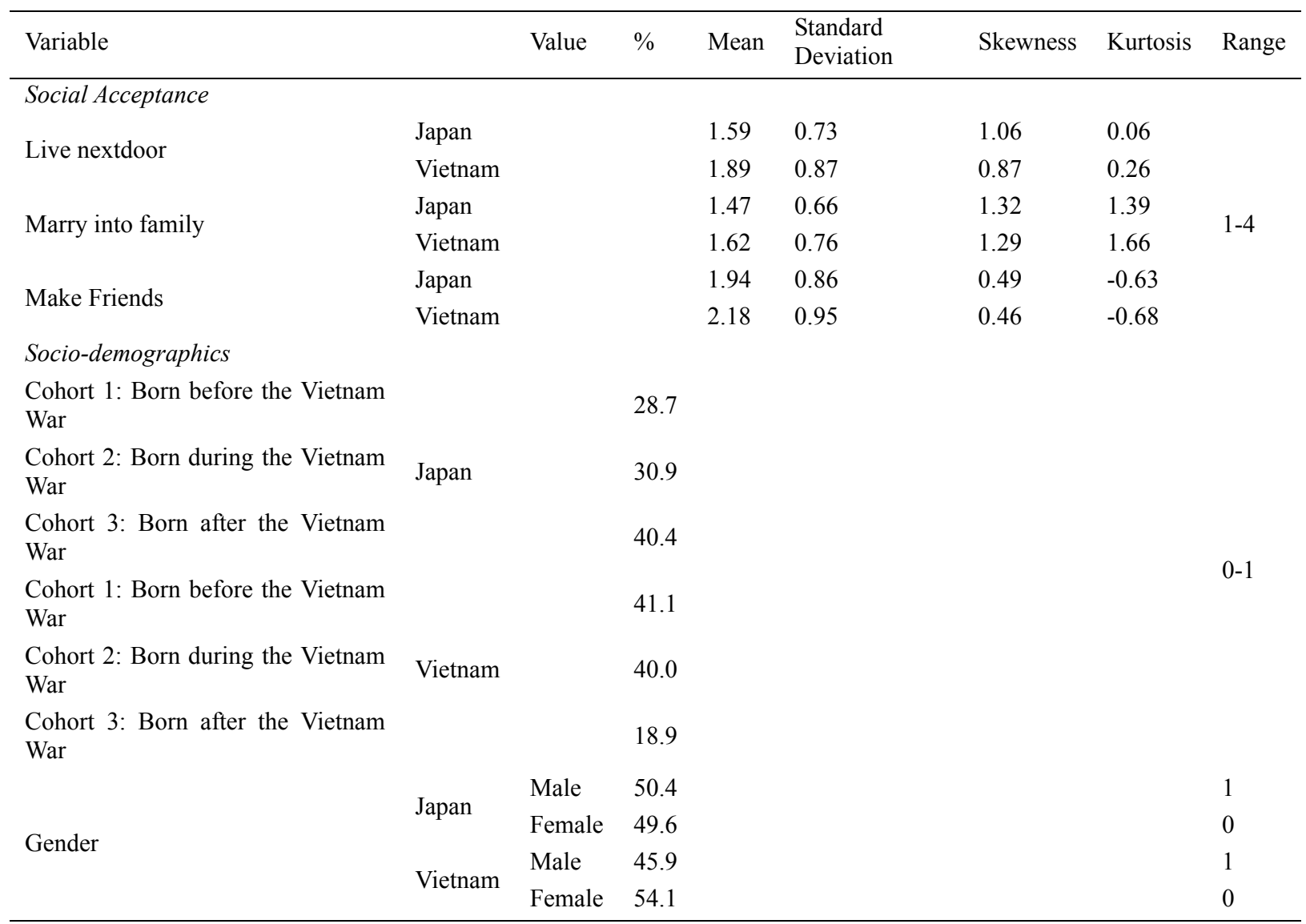




\begin{tabular}{|c|c|c|c|c|c|c|c|c|}
\hline Variable & & Value & $\%$ & Mean & $\begin{array}{l}\text { Standard } \\
\text { Deviation }\end{array}$ & Skewness & Kurtosis & Range \\
\hline \multirow{9}{*}{$\begin{array}{l}\text { Years of Education } \\
\text { (a) Elementary school degree } \\
\text { (b) Junior high school degree } \\
\text { (c) High school degree } \\
\text { (d) College degree } \\
\text { (e) University degree or higher }\end{array}$} & \multirow{4}{*}{ Japan } & $9^{(b)}$ & 6.8 & & & & & \multirow{4}{*}{$9-16$} \\
\hline & & $12^{(\mathrm{c})}$ & 55.1 & 1214 & 208 & & & \\
\hline & & $15^{(\mathrm{d})}$ & 9.2 & 10.14 & 2.00 & & & \\
\hline & & $16^{(\mathrm{e})}$ & 28.9 & & & & & \\
\hline & \multirow{5}{*}{ Vietnam } & $5^{(\mathrm{a})}$ & 14.1 & & & & & \multirow{5}{*}{$5-16$} \\
\hline & & $9^{(b)}$ & 29.2 & & & & & \\
\hline & & $12^{(\mathrm{c})}$ & 40.0 & 10.77 & 3.23 & & & \\
\hline & & $15^{(\mathrm{d})}$ & 4.3 & & & & & \\
\hline & & $16^{(\mathrm{e})}$ & 12.4 & & & & & \\
\hline \multirow{2}{*}{ Single } & Japan & & 18.9 & & & & & \multirow{4}{*}{$0-1$} \\
\hline & Vietnam & & 18.4 & & & & & \\
\hline \multirow{2}{*}{ Person Concerned } & Japan & & 12.9 & & & & & \\
\hline & Vietnam & & 23.8 & & & & & \\
\hline \multicolumn{9}{|l|}{ Psychological recognition } \\
\hline \multirow{2}{*}{ Perceived dangerousness } & Japan & & & 3.12 & 0.97 & -0.028 & -0.73 & \multirow{2}{*}{$1-5$} \\
\hline & Vietnam & & & 3.56 & 1.03 & -0.307 & -0.94 & \\
\hline \multicolumn{9}{|l|}{ Beliefs in western treatments } \\
\hline \multirow{2}{*}{ Effectiveness of psychiatrist's help } & Japan & & & 2.76 & 0.49 & -1.97 & 3.09 & \multirow{4}{*}{$1-3$} \\
\hline & Vietnam & & & 2.92 & 0.27 & -3.09 & 7.66 & \\
\hline \multirow{2}{*}{$\begin{array}{l}\text { Effectiveness of hospitalization in } \\
\text { psychiatric ward }\end{array}$} & Japan & & & 2.05 & 0.74 & -0.08 & -1.17 & \\
\hline & Vietnam & & & 2.95 & 0.23 & -3.98 & 13.96 & \\
\hline \multirow{2}{*}{$\mathrm{n}$} & Japan & 488 & & & & & & \\
\hline & Vietnam & 185 & & & & & & \\
\hline
\end{tabular}

A total of 488 Japanese and 185 Vietnamese responses were used in this analysis. From the three Japanese cohorts, the ratio was $28.7 \%$ for respondents born before the Vietnam War; those born during the war represented $30.9 \%$; and those born after $40.4 \%$. In Vietnamese cohorts, those born before the Vietnam War represent $41.1 \%$; $40.0 \%$ were born during the war; and $18.9 \%$ in the post-war period. The younger generation represented a larger portion of sample size in Japan, whereas the opposite tendency was observed in the Vietnamese data. This is because of sampling differences between the two countries. In the Japanese survey, the age range was from 20 to 69 years old and responses were collected to equal a sample size of 100, while in the Vietnamese survey, the sample was collected according to population distribution in Ho Chi Minh City. The gender ratios in both countries were well balanced.

Welch's $t$-test was applied to compare means of some variables between two countries. I calculated the respondents' educational backgrounds in years. In Vietnam, $14.1 \%$ had an elementary school level of education; there were no such cases in the Japanese data. The number of educational years reported in Japan was significantly greater than that of Vietnamese respondents $(t=86.10, P<0.001)$. This range difference in years of education may be due to the difference in two countries' educational systems. In both countries, compulsory education is enacted until junior high school, which amounts to 9 years of education from ages 6 to 15. In Vietnam, however, compulsory educational legislation does not cover all of Vietnam; therefore, except in Hanoi, there are children who finish their education in elementary school (Ministry of Foreign Affairs of Japan, 2013).

The mean ratio for the "Person concerned" was significantly higher in Vietnam than in Japan $(t=9.72, P<0.01)$. The mean of the three social acceptance variables was also significantly higher in Vietnam. The values for each of the three variables' Welch's $t$-tests were as follows: "Live next door" $(t=17.49, P<0.001)$; "Marry into family" $(t=6.14, P<0.05)$; "Make friends" ( $t=9.36, P<0.05)$. On average, Vietnamese people are more accepting of those with schizophrenia than the Japanese. The mean of "Perceived dangerousness" was significantly higher in Vietnam than in Japan; thus, Vietnamese people tend to more strongly regard persons with schizophrenia as dangerous than the Japanese $(t=24.92, P<0.001)$. However, according to Nakane (2010), there is a discrepancy between Japanese respondents' personal views and their estimation of others' views toward schizophrenia, including perceived dangerousness. This was a particular tendency of Japanese respondents, compared to those from Australia. Nakane suggested, as a possible interpretation, that this 
phenomenon indicates that the Japanese prefer hiding negative personal views; thus, higher response rates to the question of estimation of others' view regarding perceived dangerousness might reflect the respondents' real opinions and responses related to personal view might be intentionally low (ibid). In this study, the Japanese mean of estimation of others' view was slightly higher than the Vietnamese one (mean $(\mathrm{Japan} / \mathrm{Vietnam})=$ $3.65 / 3.50, t=3.06, P<0.10$ ). Though it is important to take into consideration this Japanese inconsistency, I used respondents' personal views of perceived dangerousness as a psychological variable because there are no further clear investigations for it. Vietnamese people were significantly more confident in the effectiveness of psychiatric care $(t=26.77, P<0.001)$ and hospitalization than the Japanese $(t=570.01, P<0.001)$. Overall, Vietnamese respondents had more frequent contact with and tolerant attitudes toward people who have schizophrenia than did the Japanese surveyed.

Although these comparisons of mean between Japan and Vietnam indicate that the two countries do not share similar tendencies, we do see that similarities between perceived dangerousness and social acceptance exist across both cultures, as former studies have emphasized.

\subsection{Relation between Perceived Dangerousness and Social Acceptance in Japan and Vietnam}

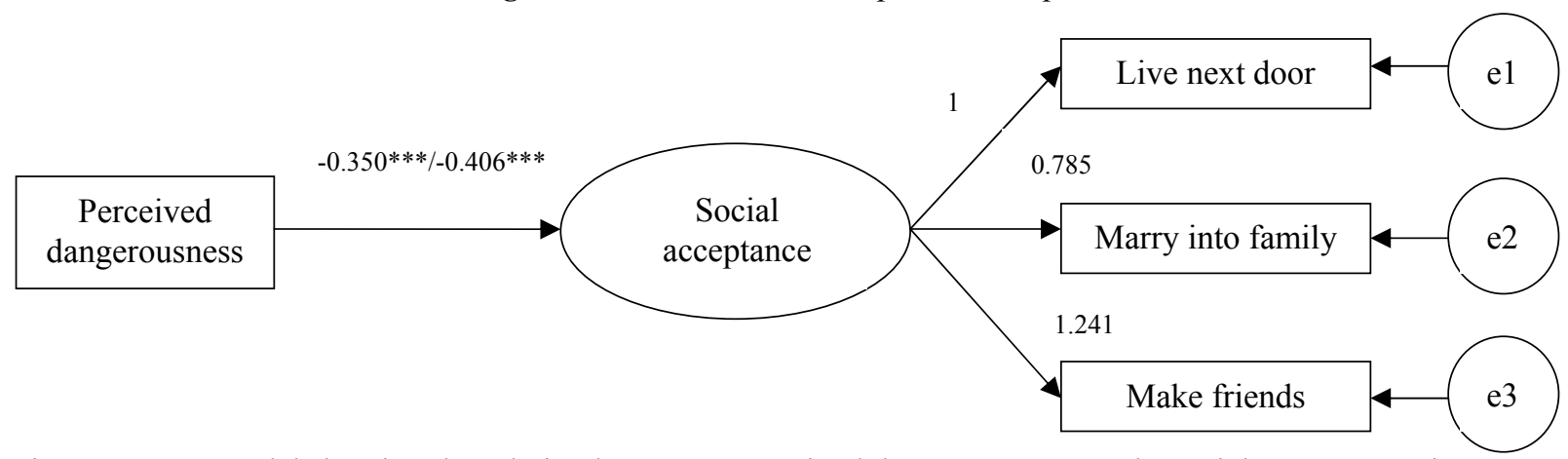

Figure 1. Base model showing the relation between "Perceived dangerousness" and "Social acceptance" in Japan and Vietnam

Note: Japan $(n)=488$, Vietnam $(n)=185 ; \mathrm{CFI}=0.993 ;$ RMSEA $=0.048,{ }^{* * *} P<0.001$

The Japanese unstandardized regression coefficient $(B)$ of "Perceived dangerousness" was estimated as -0.202 and -0.238 in the Vietnamese group. In this figure, standardized regression coefficient of Japanese group concerning perceived dangerousness $(\beta=-0.350)$ is indicated on left side on the path to "Social acceptance" and the Vietnamese one is indicated on right side $(\beta=-0.406)$.

Factor loadings for latent constructs of social acceptance indicated are unstandardized.

I examined whether the causal relation between perceived dangerousness and the latent factors of social acceptance, shown repeatedly in other studies, were also observed in Vietnam and Japan. The base model yielded a CFI of 0.993 and a RMSEA of 0.048 , showing that this model fits the data reasonably well (Figure 1). All the estimated values of factor loadings for latent constructs of social acceptance were constrained to be equal between the two countries, which were significant at $P<0.001$. In both countries, there existed the same causal relation between perceived dangerousness and social acceptance; a higher score for the former is likely to reduce the score for social acceptance. Since the standardized regression coefficient $(\beta)$ for the Vietnamese group ( $\beta=$ $-0.406)$ was higher than that of the Japanese group $(\beta=-0.350)$, the impact of perceived dangerousness on social acceptance is stronger in Vietnam than in Japan. Since the relation between these two factors is confirmed by these data, it can be said that they reflect the tendencies related to social acceptance shown in other studies, therefore the first hypothesis (HP-1) was supported. As a next step, I examined knowledge and social instability hypotheses by adding the rest the variables in the following models. 


\subsection{Structural Differences in Causal Factors of Social Acceptance between Japan and Vietnam}

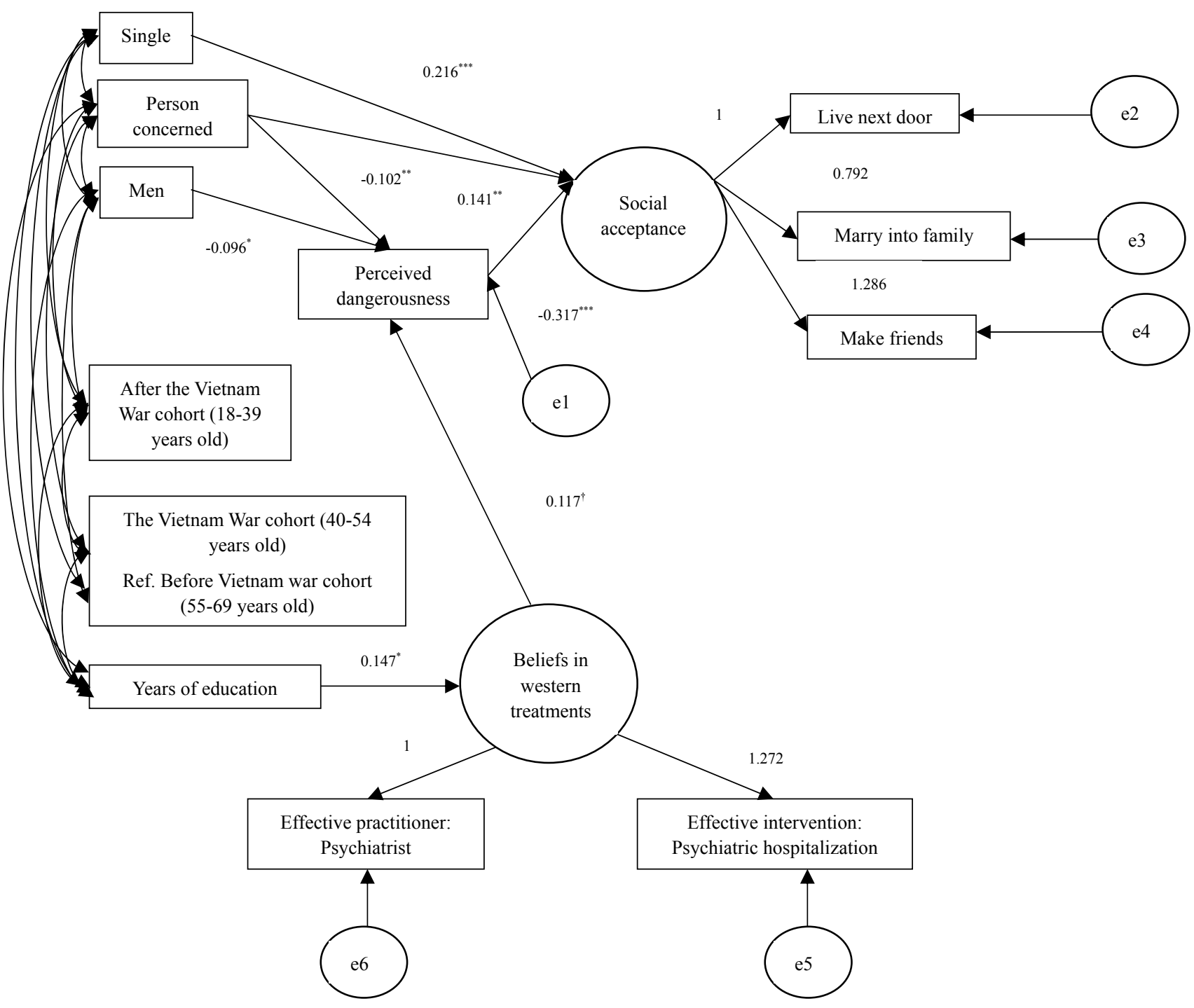

Figure 2. Factors of Japanese "Social acceptance" toward persons with schizophrenia

Note: Japan $(\mathrm{n})=488 ; \mathrm{CFI}=0.974 ; \mathrm{RMSEA}=0.035 ;{ }^{* * *} P<0.001 ;{ }^{* *} P<0.01 ;{ }^{*} P<0.05 ;{ }^{\dagger} P<0.10$

All parameters indicated in this figure are standardized regression coefficients $(\beta)$, except the factor loadings for latent constructs of "Social acceptance" and "Beliefs in Western treatments."

Factor loadings of the three variables of "Social acceptance" and "Beliefs in Western treatments" are constrained equally between the two countries (Figure 2 and Figure 3).

Only significant relations are described in Figure 2 and Figure 3.

Model fitness of CFI and RMSEA are remarked in Figure 2. 


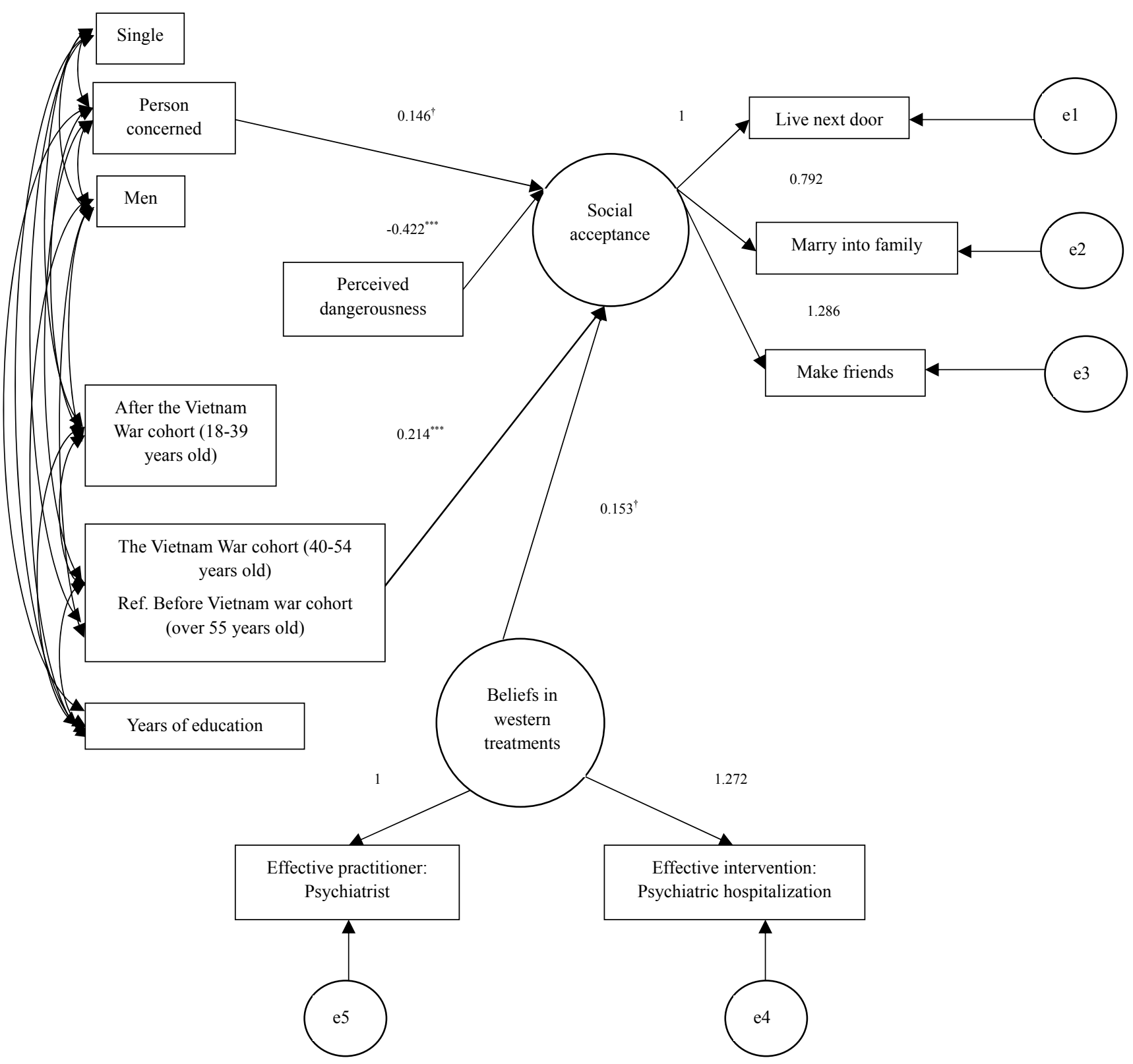

Figure 3. Factors of Vietnamese "Social acceptance" toward the persons with schizophrenia

Note. Vietnam (n) $=185 ;{ }^{* * *} P<0.001 ;{ }^{* *} P<0.01 ;{ }^{*} P<0.05 ;{ }^{\dagger} P<0.10$

Figure 2 and Figure 3 report SEM analysis results exploring the effects of war-related cohorts and other socio-demographic variables related to "Beliefs on Western psychiatric treatment", "Perceived dangerousness", and "Social acceptance". Indices of model fit $(\mathrm{CFI}=0.974$; RMSEA $=0.035)$ show that the models fit the data reasonably well. In addition, the power was 0.999 yielded in the Japanese model and 0.946 in the Vietnam model. Therefore, both models also had acceptable fit for the population data. (Note 3) I treated the variables of the two latent constructs of "Social acceptance" and "Beliefs in Western treatments" as continuous factor indicators to keep equivalent structures in both countries. The intercepts of these two latent constructs were fixed at zero in the Japanese model, but estimated freely in Vietnamese model. The means of the two were also fixed at zero and the factor loadings were constrained to be equal in both countries, which mean that my comparisons were not complete but approximate for the structures of these two latent constructs.

Two remarkable differences were observed between two countries. First, in the Vietnamese model (Figure 3), the Vietnam War cohorts strongly affected social acceptance and were the most influential factors. People born 
during the Vietnam War showed significantly greater acceptance of persons with schizophrenia $(\beta=0.214)$ than those born before the war. On the other hand, no cohort effect was observed in Japan (Figure 2). Second, while beliefs in Western treatments directly increased social acceptance in the Vietnamese model $(\beta=0.153$ in Figure $3)$, it increased perceived dangerousness in the Japanese model $(\beta=0.117$ in Figure 2.) In addition, in the Japanese model, years of education enforced beliefs in Western treatments $(\beta=0.147)$.

The effect of contact in the Japanese model was apparent when the respondents chose the "Person concerned" category; perceived dangerousness was reduced $(\beta=-0.102)$ and they were likely to be more socially accepting $(\beta=0.141)$ (Figure 2). In Vietnamese model, this variable increased social acceptance directly $(\beta=0.146)$, but had no significant effect on perceived dangerousness.

For the "Single" $(\beta=0.216)$ and "Men" $(\beta=-0.096)$ categories, significant effects were observed in the Japanese model. Single respondents showed greater acceptance toward persons with schizophrenia. Japanese women, compared to men, more strongly perceived those with schizophrenia as dangerous. On the other hand, other socio-demographic factors had no significant effects on perceived dangerousness and beliefs in Western treatments in Vietnam model.

\section{Discussion}

This study investigated the relationship between the socio-demographic and psychological factors of social acceptance of persons with schizophrenia by comparing two culturally different countries, Japan and Vietnam. By focusing on two hypotheses, two important conclusions can be derived from this analysis. First, with respect to the knowledge hypothesis, I discerned the effects of education-based knowledge as a variable of "Beliefs in Western treatments" and contact-based experience as a variable of "Person concerned." As the contact hypothesis indicated, the variable of person concerned had positive effects on promoting social acceptance in both countries; however, beliefs in Western treatments had a contradictory effect on social acceptance. In Japan, highly educated people had stronger beliefs in Western treatments, which increased their perception of dangerousness and promoted a decline in social acceptance. This explains the paradoxical outcomes of educational programs. Societies where Western psychiatric treatments are already diffused and have a history of psychiatric hospitals as surveillance systems for patients regard persons with schizophrenia as dangerous to others. People from these societies who acquire knowledge on the effectiveness of Western psychiatric treatments are only provided with new perspectives on the trends of recent psychiatric treatments by the educational programs on mental health literacy; they do not provide these people with any opportunity to reflect or regret the history of the Western mental health system. Support for the institutionalization of patient care is linked to the public's belief that Western treatments and surveillance in hospitals are effective in dealing with patients that are considered dangerous. As a result, this belief reduces their social acceptance. On the other hand, education-based knowledge did not stimulate the image of asylum of Vietnamese people. Because they have not gone through the institutionalization history of psychiatric wards, it directly promoted their social acceptance. Therefore, it can be said that the second hypothesis (HP-2) was supported.

Second, age was found to produce a nonlinear effect only in the Vietnamese models; former studies indicated a linear effect. Vietnamese society had suffered the crucial scars of war. The cohort that grew up during that period showed greater acceptance toward those with schizophrenia. Conversely, no drastic economic or political changes had taken place during the same period in Japan; therefore, the effect of cohort was not observed. We can conclude that the social instability hypothesis (HP-3) was supported.

The present analysis has implications for reducing the stigmatization of schizophrenia. I hope that my findings from Japan will contribute not only to explain to public that people with schizophrenia are not always dangerous but also that the current aim of care should be to deinstitutionalize patient in countries where Western psychiatry has already been widely adopted. In addition, to elicit more positive effects from educational programs, generational background and social change should be points to consider.

To assess potential difficulties in cross-cultural studies, the validity of questions always needs to be taken into consideration. The "Person concerned" variable had positive effects on perceived dangerousness and social acceptance in Japan, while it only positively affected social acceptance in Vietnam. Considering the similar manifestation rate of schizophrenia in the two societies (Jablensky et al., 1992), it may be said that this variable measured the situation of respondents differently in Japan than Vietnam. It could mean that Japanese participants had family members (a close relative or someone within a nuclear family) or close friends with similar problems to the vignette person. Vietnamese responses included more distant relatives and extended family. This is consistent with the difference in frequency results between two countries shown in Table1; twice as many Vietnamese participants responded that they have a member of the "family or friends" who have schizophrenia 
as Japanese respondents did. This difference in family composition might mean that Japanese participants had more frequent contact with people that have schizophrenia than Vietnamese respondents did. It may be the reason why the person concerned variable influenced both perceived dangerousness and social acceptance only in the Japanese model and had no effect on perceived dangerousness in the Vietnamese model. To conduct cross-cultural or international surveys, it is necessary to deliberate not only on the equivalence of the linguistic translation of variables but also on the metric equivalence of the concept that each variable intends to measure. Descriptions of each country or society's characteristics can be well archived in international comparisons. As globalization influences the psychiatric domain and mental health policies of most of countries, the importance of international surveys will increase significantly. In psychiatric epidemiology, international surveys such as the INDIGO study (Thornicroft et al., 2009), GAMIAN study (eg., Evans-Lacko et al., 2012) and SGC-MHS study (eg., Olafsdottir \& Pescosolido, 2011) have gradually been adopted. To create well-designed questionnaires covering several societies, psychiatric researchers need to cooperate more openly with researchers in other fields of study such as sociology, anthropology, or linguistics.

This study contains the following limitations: first, the sample sizes were limited and the sampling methods were inconsistent between the two countries. Taking into consideration that sample size influenced the power, especially in the base model of "Figure 1" (Note 3), it is difficult to generalize present findings to the entire populations of both countries. However, the results show great improvement of population's data model fit in Figure 2 and Figure 3, this study does suggest structural differences concerning the effect of the knowledge and of the cohorts appearing in the cultural contexts of Asian societies.

The Japanese samples were gathered from 25 medium to large-sized cities, whereas those of Vietnam were collected from only one large city whose sampling covered rural areas. Given the effect of urbanicity (Economou et al., 2009; Stuart \& Arboleda-Florez, 2001), there might be potential differences between urban and rural areas concerning the social acceptance toward persons with schizophrenia reflected in the Vietnam data that is not seen in the Japanese data. On the other hand, there may exist a spurious correlation between urbanicity and social acceptance. Urbanicity correlates strongly to education-based knowledge (Griffiths et al., 2009) and the effect of urbanicity is not significant when controlling for the level of education (Adewuya \& Makanjuola, 2008; Foulkner et al., 2010). In this study, while variables on residential areas were lacking, educational level was controlled (Figure 2 and Figure 3), thus the influence of urbanicity was likely mitigated. In addition to what has been noted in previous studies, Ho Chi Minh City is one of the largest cities in Vietnam and has developed progressively over last decades. (Note 4) Thus, while the effect of urbanicity on social acceptance in the two countries cannot be denied, it does not have the potentially fatal influences on the statistical estimations this study.

Second, there was a four-year lag in data collection between the two surveys. Although there were no remarkable political changes in mental health services or any anti-stigma movements in Japan and Vietnam during the period in which the two surveys were conducted, the data did not reflect exactly the present state of social acceptance in both countries. In addition, taking a consideration of recent trend of a decline in social acceptance toward persons with schizophrenia in Western societies (Schomerus et al., 2012), the same tendency might be likely observed today in both countries.

Third, I used data from only two countries to examine the hypotheses. Findings from this study, therefore, are difficult to generalize to any other countries. I also could not add other variables in the analysis to construct the latent factors of social acceptance and beliefs in Western treatments because of the model's fitness and the number of variables' missing data. Thus, the study's factors cannot be said to exactly represent the respondents' tolerance and education-based knowledge. To more validly test the hypotheses suggested in this study, the wording of questions and sampling should be elaborated at the survey planning stage.

Despite these limitations, this study makes a contribution toward solving the paradoxical effect of enlightenment toward increasing mental health literacy and in showing the importance of considering generational characteristics.

\section{Acknowledgements}

The Vietnamese survey was funded by "A Research Base for Conflict Studies in the Humanities in 2008," a research grant program from the Graduate School of Human Sciences of Osaka University in Japan. The survey was carried out under the direction of Professor Masaharu Uemoto at Kobe City College of Nursing and Lecturer Ai Miura at Baika Women's University. The author is permitted to use their data and shows grateful acknowledgement to them. Professor Emeritus Yoshibumi Nakane and Professor Hideyuki Nakane at Nagasaki University, Associate Professor Kumiko Yoshioka at Fukuoka University also deserve grateful 
acknowledgements for permitting the use of their Japanese survey data. The contributors mentioned above provided primary data exclusively. The author is solely responsible for the analysis and interpretations in this article.

The author is grateful to Mr. Makoto Hiramatsu, the research assistant at Research Support System at Osaka University, for his assistance in gathering population data for Japan and Vietnam.

In addition, the author is grateful to anonymous reviewers for their supportive suggestions.

This work was partially supported by a Grant-in-Aid for Japan Society for the Promotion of Science (JSPS) Fellows.

\section{References}

Adewuya, A. O., \& Makanjuola, R. O. A. (2008). Social distance towards people with mental illness in southwestern Nigeria. Australian \& New Zealand Journal of Psychiatry, 42(5), 389-395. http://dx.doi.org $/ 10.1080 / 00048670801961115$

Allport, G. W. (1979). The nature of prejudice. Reading, Mass.; Tokyo: Addison-Wesley.

Angermeyer, M. H. (2003). The Stigma of mental illness: Effects of labelling on public attitudes towards people with mental disorder. Acta Psychiatrica Scandinavica, 108, 304-309. http://dx.doi.org/10.1034/j.1600-0447. 2003.00150.x

Brown, R. (1995). Prejudice : Its social psychology. Oxford ; Cambridge, Mass.: Blackwell.

Cutler, J. L., Harding, K. J., Hutner, L. A., Cortland, C., \& Graham, M. J. (2012). Reducing medical students' stigmatization of people with chronic mental illness: a field intervention at the "living museum" state hospital art studio. Academic Psychiatry: The Journal of the American Association of Directors of Psychiatric Residency Training and the Association for Academic Psychiatry, 36(3), 191-196. http://dx.doi. org/10.1176/appi.ap.10050081

Desforges, D. M., Lord, C. G., Ramsey, S. L., Mason, J. A., Van Leeuwen, M. D., West, S. C., \& Lepper, M. R. (1991). Effects of structured cooperative contact on changing negative attitudes toward stigmatized social groups. Journal of Personality and Social Psychology, 60(4), 531-544. http://dx.doi.org/10.1037/00223514.60.4.531

Durand-Zaleski, I., Scott, J., Rouillon, F., \& Leboyer, M. (2012). A first national survey of knowledge, attitudes and behaviours towards schizophrenia, bipolar disorders and autism in France. BMC Psychiatry, 12, 128. http://dx.doi.org/10.1186/1471-244X-12-128

Economou, M., Richardson, C., Gramandani, C., Stalikas, A., \& Stefanis, C. (2009). Knowledge about schizophrenia and attitudes towards people with schizophrenia in Greece. The International Journal of Social Psychiatry, 55(4), 361-371. http://dx.doi.org/10.1177/0020764008093957

Elder, G. H. (1984). Children of the Great Depression : Social change in life experience. Chicago: University of Chicago Press.

Evans-Lacko, S., Brohan, E., Mojtabai, R., \& Thornicroft, G. (2012). Association between public views of mental illness and self-stigma among individuals with mental illness in 14 European countries. Psychological Medicine, 42(8), 1741-1752. http://dx.doi.org/10.1017/S0033291711002558

Foulkner, G., Irving, H., Paglia-Boak, A., \& Adlaf, E. (2010). Adolescent knowldege of schizophrenia and social distancing. Journal of Community Psychology. http://dx.doi.org/10.1002/jcop.20406

General Statistics Office of Vietnam. (2007). Average population by province. Retrieved April 9, 2015, from http://www.gso.gov.vn/default_en.aspx?tabid=774

Goffman, E. (1961). Asylums : Essays on the social situation of mental patients and other inmates. New York: Doubleday.

González-Torres, M. A., Oraa, R., Arístegui, M., Fernández-Rivas, A., \& Guimon, J. (2007). Stigma and discrimination towards people with schizophrenia and their family members: A qualitative study with focus groups. Soc. Psychiatry Psychiatr Epidemiol, 42, 14-23. http://dx.doi.org/10.1007/s00127-006-0126-3

Griffiths, K. M., Christensen, H., \& Jorm, A. F. (2009). Mental health literacy as a function of remoteness of residence: an Australian national study. BMC Public Health, 9, 92. http://dx.doi.org/10.1186/1471-2458$9-92$

Griffiths, K. M., Nakane, Y., Christensen, H., Yoshioka, K., Jorm, A. F., \& Nakane, H. (2006). Stigma in 
response to mental disorders: A comparison of Australia and Japan. BMC Psychiatry, 6, 21. http://dx.doi.org /10.1186/1471-244X-6-21

Hancock, G. R., \& French, B. F. (2013). Power Analysis in Structural Equation Modeling. In G. R. Hancock, \& R. O. Mueller (Eds.), Structural Equation Modeling: A Second Course-A volume in the series: Quantitative Methods in Education and the Behavioral Sciences: Issues, Research, and Teaching (2nd ed., pp. 117-162). Information Age Pub Inc.

Inglehart, R. (1990). Culture shift in advanced industrial society. Princeton, N.J.: Princeton University Press.

Jablensky, A., Sartorius, N., Ernberg, G., Anker, M., Korten, A., Cooper, J. E., ... Bertelsen, A. (1992). Schizophrenia: Manifestations, incidence and course in different cultures: A World Health Organization Ten-Country Study. Psychological Medicine. Monograph Supplement, 20, 1-97. http://dx.doi.org/10.1017/ S0264180100000904

Jorm, A. F., Korten, A. E., Jacomb, P. A., Christensen, H., Rodgers, B., \& Pollitt, P. (1997). Mental health literacy: a survey of the public's ability to recognise mental disorders and their beliefs about the effectiveness of treatment. Medical Journal of Australia. The Medical Journal of Australia, 166(4), 182. Retrieved from https://www.mja.com.au/journal/1997/166/4/mental-health-literacy-survey-publics-abilityrecognise-mental-disorders-and

Kelly, C. M., Jorm, A. F., \& Wright, A. (2007). Improving mental health literacy as a strategy to facilitate early intervention for mental disorders. Medical Journal of Australia. The Medical Journal of Australia, 187(7), S26-S30. Retrieved from https://www.mja.com.au/journal/2007/187/7/improving-mental-health-literacystrategy-facilitate-early-intervention-mental

Lauber, C., Nordt, C., Falcato, L., \& Rössler, W. (2004). Factors Influencing Social Distance Toward People with Mental Illness. Community Mental Health Journal, 40(3), 265-274. http://dx.doi.org/10.1023/B:COMH. $0000026999.87728 .2 \mathrm{~d}$

Link, B. G., Phelan, J. C., Bresnahan, M., Stueve, A., \& Pescosolido, B. A. (1999). Public conceptions of mental illness: labels, causes, dangerousness, and social distance. American Journal of Public Health, 89(9), 1328-1333. http://dx.doi.org/10.2105/AJPH.89.9.1328

Maccallum, R. C., Browne, M. W., \& Sugawara, H. M. (1996). Power analysis and determination of sample size.pdf. Psychological Methods, 1(2), 130-149. http://dx.doi.org/10.1037/1082-989X.1.2.130

Maccallum, R., Lee, T., \& Browne, M. W. (2010). The Issue of Isopower in Power Analysis for Tests of Structural Equation Models. Structural Equation Modeling: A Multidisciplinary Journal, 17(1), 23-41. http://dx.doi.org/10.1080/10705510903438906

Marshall, M., Lewis, S., Lockwood, A., Drake, R., Jones, P., \& Croudace, T. (2005). Association between duration of untreated psychosis and outcome in cohorts of first-episode patients: A systematic review. Archives of General Psychiatry, 62(9), 975-983. http://dx.doi.org/10.1001/archpsyc.62.9.975

Ministry of Foreign Affairs of Japan. (2013). Educational information about foreign countries: Viet Nam. Retrieved April 20, 2015, from http://www.mofa.go.jp/mofaj/toko/world_school/01asia/infoC11600.html

Ministry of Health. (2011). Average length of stay for estimated discharged patients (per month). Retrieved from http://www.mhlw.go.jp/english/database/db-hss/d1/sps_2011_03.pdf

Ministry of Health. (2012). Survey of medical institutions (Iryou-shisetsu tyousa: Japanese). Retrieved February 12, 2014, from http://www.mhlw.go.jp/toukei/saikin/hw/iryosd/12/dl/1-1.pdf

Mino, Y., Yasuda, N., Tsuda, T., \& Shimodera, S. (2001). Effects of a one-hour educational program on medical students' attitudes to mental illness. Psychiatry and Clinical Neurosciences, 55(5), 501-507. http://dx.doi. org/10.1046/j.1440-1819.2001.00896.x

Nakane, Y. (2010). Comparative study of mental health between Japan and Australia (Seishin hoken ni kansuru Nichi-Ou hikaku kyoudou kenkyuu: Japanese). In Y. Nakane, Y. Kumiko, \& N. Hideyuki (Eds.), The Japanese views toward schizophrenia and depression: Aiming at mental barrier-free (Kokoro no barrier-free wo mezashite: Nihonjin ni totte no utsu-byou, tougousittyou-syou) (pp. 45-83). Tokyo: Keisou Syobou.

Nakane, Y., Jorm, A. F., Yoshioka, K., Christensen, H., Nakane, H., \& Griffiths, K. M. (2005). Public beliefs about causes and risk factors for mental disorders: A comparison of Japan and Australia. BMC Psychiatry, 5, 33. http://dx.doi.org/10.1186/1471-244X-5-33 
Olafsdottir, S., \& Pescosolido, B. A. (2011). Constructing illness: how the public in eight Western nations respond to a clinical description of "schizophrenia". Social Science \& Medicine (1982), 73(6), 929-938.

Pinfold, V., Huxley, P., Thornicroft, G., Farmer, P., Toulmin, H., \& Graham, T. (2003). Reducing psychiatric stigma and discrimination--evaluating an educational intervention with the police force in England. Social Psychiatry and Psychiatric Epidemiology, 38(6), 337-344.

Pinfold, V., Thornicroft, G., Huxley, P., \& Farmer, P. (2005). Active ingredients in anti-stigma programmes in mental health. International Review of Psychiatry (Abingdon, England), 17(2), 123-131. http://dx.doi.org/10. $1080 / 09540260500073638$

Preacher, K. J., \& Coffman, D. L. (2006). Computing power and minimum sample size for RMSEA. Retrieved from http://quantpsy.org/

Primavera, D., Bandecchi, C., Lepori, T., Sanna, L., Nicotra, E., \& Carpiniello, B. (2012). Does duration of untreated psychosis predict very long term outcome of schizophrenic disorders? Results of a retrospective study. Annals of General Psychiatry, 11(1), 21. http://dx.doi.org/10.1186/1744-859X-11-21

Schomerus, G., Schwahn, C., Holzinger, A., Corrigan, P. W., Grabe, H. J., Carta, M. G., \& Angermeyer, M. C. (2012). Evolution of public attitudes about mental illness: A systematic review and meta-analysis. Acta Psychiatrica Scandinavica, 125(6), 440-452. http://dx.doi.org/10.1111/j.1600-0447.2012.01826.x

Statistics Bureau of Japan, M. of I. A. and C. (2003). Population by Sex for Prefectures: Total population, Japanese population. Retrieved from http://www.e-stat.go.jp/SG1/estat/ListE.do?lid=000001010882

Stuart, H., \& Arboleda-Florez, J. (2001). Community Attitudes Toward People With Schizophrenia. Canadian Journal of Psychiatry, 46(3), 245-252.

Tanaka, G., Inadomi, H., Kikuchi, Y., \& Ohta, Y. (2004). Evaluating stigma against mental disorder and related factors. Psychiatry and Clinical Neurosciences, 58(5), 558-566. http://dx.doi.org/10.1111/j.1440-1819.2004. 01300.x

Tanaka, G., Ogawa, T., Inadomi, H., Kikuchi, Y., \& Ohta, Y. (2003). Effects of an educational program on public attitudes towards mental illness. Psychiatry and Clinical Neurosciences, 57(6), 595-602. http://dx.doi.org /10.1046/j.1440-1819.2003.01173.x

The Wold Bank. (n. d.). Population growth (annual \%). Retrieved April 9, 2015, from http://data.worldbank.org/indicator/SP.POP.GROW

The World Psychiatric Association. (2005). The wpa global programme to reduce stigma and discrimination because of schizophrenia. Schizophrenia Open the Doors Training Manual. Retrieved February 9, 2014, from http://www.open-the-doors.com/english/media/Training_8.15.05.pdf

Thirthalli, J., Channaveerachari, N. K., Subbakrishna, D. K., Cottler, L. B., Varghese, M., \& Gangadhar, B. N. (2011). Prospective study of duration of untreated psychosis and outcome of never-treated patients with schizophrenia in India. Indian Journal of Psychiatry, 53(4), 319-323. http://dx.doi.org/10.4103/00195545.91905

Thornicroft, G., Brohan, E., Rose, D., Sartorius, N., \& Leese, M. (2009). Global pattern of experienced and anticipated discrimination against people with schizophrenia: A cross-sectional survey. Lancet, 373(9661), 408-415. http://dx.doi.org/10.1016/S0140-6736(08)61817-6

Uçok, A., Brohan, E., Rose, D., Sartorius, N., Leese, M., Yoon, C. K., ... Thornicroft, G. (2012). Anticipated discrimination among people with schizophrenia. Acta Psychiatrica Scandinavica, 125(1), 77-83. http://dx. doi.org/10.1111/j.1600-0447.2011.01772.x

Uemoto, M. (2009). Southeast Asia: Vietnam (Japanese). In N. Shinfuku, \& K. Asai (Eds.), World mental health services: Current situations and future prospects (Sekai no seishin-hoken iryou: Genjyou rikai to kongo no tenbou) (2nd ed., pp. 107-111). Tokyo: Helth Syuppan.

Uemoto, M., \& Miura, A. (2012). A case study of cross-cultural psychiatry in Vietnam and Japan (Tabunka-kan seishin-igaku no jirei-kenkyuu toshiteno Vietnum-Japan: Japanese). In M. Ikeda (Ed.), A series of Conflict studies in the humanities 2 (Conflict no jinbungaku 2: Conflict to imin, atarashii kenkyuu no syatei) (Vol. 2, pp. 241-266). Suita: Osaka University press.

Vuong, D. A., Van Ginneken, E., Morris, J., Ha, S. T., \& Busse, R. (2011). Mental health in Vietnam: Burden of disease and availability of services. Asian Journal of Psychiatry, 4(1), 65-70. http://dx.doi.org/10.1016/j.ajp. 2011.01.005 
Warner, R. (1994). Recovery from Schizophrenia: Psychiatry and Political Economy (2nd ed.). London: Routledge.

Yamaguchi, S., Mino, Y., \& Uddin, S. (2011). Strategies and future attempts to reduce stigmatization and increase awareness of mental health problems among young people: A narrative review of educational interventions. Psychiatry and Clinical Neurosciences, 65(5), 405-415. http://dx.doi.org/10.1111/j.1440-1819. 2011.02239.x

Yamaguchi, S., Wu, S. I., Biswas, M., Yate, M., Aoki, Y., Barley, E. A., \& Thornicroft, G. (2013). Effects of short-term interventions to reduce mental health-related stigma in university or college students: A systematic review. The Journal of Nervous and Mental Disease, 201(6), 490-503. http://dx.doi.org/10.1097/ NMD.0b013e31829480df

Yamamoto, K. (2001). Asia and Oceania: Vietnam (Japanese). In N. Shinfuku, \& K. Asai (Eds.), World mental health services: Current situations and future prospects (Sekai no seishin-hoken iryou: Genjyou rikai to kongo no tenbou) (1st ed., pp. 102-104). Tokyo: Helth Syuppan.

Yoshioka, K. (2010). Japanese mental health litteracy (Nihon-jin no metal health litteracy). In Y. Nakane, K. Yoshioka, \& H. Nakane (Eds.), The Japanese views toward schizophrenia and depression: Aiming at mental barrier-free (Kokoro no barrier-free wo mezashite: Nihonjin ni totte no utsu-byou, tougousittyou-syou) (pp. 15-43). Tokyo: Keisou Syobou.

\section{Notes}

Note 1. In the sampling strategy, two lands 'Hokkaido' and 'Shikoku' were excluded. City size of twenty-five sites were more than middle. These sampling limitations were inevitable due to research financial and manpower strains (Yoshioka, 2010). The whole country population of Japan was estimated 127,619,000 in 2003. When excluding Hokkaido and Shikoku population size of 117,833,000 was reported(Statistics Bureau of Japan, 2003).

Note 2. The Vietnam samples included rural area residents. The whole country population of Vietnam was 84,218,500 in 2007 and that of Ho Chi Minh City was 6,725,300 (General Statistics Office Of Vietnam, 2007).

Note 3. For computing the power of models by RMSEA (Hancock \& French, 2013; Maccallum, Browne, \& Sugawara, 1996; Maccallum, Lee, \& Browne, 2010), the author used Preacher and Coffman's (2006) on-line utility (setting Alpha to 0.05, degrees of freedom to 53, Null RMSEA to 0.08 and Alt. RMSEA to 0.035).

Concerning base model of Figure 1, the power of Japanese model yielded of 0.457 and of 0.189 for Vietnam model (setting Alpha to 0.05, degrees of freedom to 6, Null RMSEA to 0.08 and Alt. RMSEA to 0.048). As for the base models, it should be noted that, to have a 0.80 probability for an acceptable data-model fit (setting Alpha to 0.05), the present studies in both countries needed a minimum of 1110 cases.

Note 4. The population growth rates in Ho chi Minh City launched at as 3.71in 2005 and shifted to 1.94 in 2012, and that of Vietnam whole country was 1.17 in 2005 and 1.06 in 2012 (General Statistics Office Of Vietnam, 2007). On the other hand, that was 0.0 in 2005 and -0.2 in 2012 in Japan (The Wold Bank, n. d.).

\section{Copyrights}

Copyright for this article is retained by the author(s), with first publication rights granted to the journal.

This is an open-access article distributed under the terms and conditions of the Creative Commons Attribution license (http://creativecommons.org/licenses/by/3.0/). 